\title{
Lifestyle, social factors, and survival after age 75: population based study
}

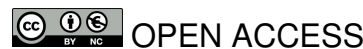

\author{
Debora Rizzuto PhD student ${ }^{1}$, Nicola Orsini associate professor ${ }^{2}$, Chengxuan Qiu associate \\ professor $^{1}$, Hui-Xin Wang senior researcher ${ }^{1}$, Laura Fratiglioni professor ${ }^{13}$
}

${ }^{1}$ Aging Research Center, Department of Neurobiology, Health Care Sciences and Society, Karolinska Institutet and Stockholm University, 11330 Stockholm, Sweden ; ${ }^{2}$ Unit of Nutritional Epidemiology and Unit of Biostatistics, National Institute of Environmental Medicine, Karolinska Institutet; ${ }^{3}$ Stockholm Gerontology Research Center, Stockholm

\begin{abstract}
Objective To identify modifiable factors associated with longevity among adults aged 75 and older.

Design Population based cohort study.

Setting Kungsholmen, Stockholm, Sweden.

Participants 1810 adults aged 75 or more participating in the Kungsholmen Project, with follow-up for 18 years.

Main outcome measure Median age at death. Vital status from 1987 to 2005.

Results During follow-up 1661 (91.8\%) participants died. Half of the participants lived longer than 90 years. Half of the current smokers died 1.0 year ( $95 \%$ confidence interval 0.0 to 1.9 years) earlier than non-smokers. Of the leisure activities, physical activity was most strongly associated with survival; the median age at death of participants who regularly swam, walked, or did gymnastics was 2.0 years $(0.7$ to 3.3 years) greater than those who did not. The median survival of people with a low risk profile (healthy lifestyle behaviours, participation in at least one leisure activity, and a rich or moderate social network) was 5.4 years longer than those with a high risk profile (unhealthy lifestyle behaviours, no participation in leisure activities, and a limited or poor social network). Even among the oldest old (85 years or older) and people with chronic conditions, the median age at death was four years higher for those with a low risk profile compared with those with a high risk profile.
\end{abstract}

Conclusion Even after age 75 lifestyle behaviours such as not smoking and physical activity are associated with longer survival. A low risk profile can add five years to women's lives and six years to men's. These associations, although attenuated, were also present among the oldest old ( $\geq 85$ years) and in people with chronic conditions.

\section{Introduction}

An increasing proportion of the population in the developed countries lives to very advanced age. ${ }^{1}$ Although our current knowledge on the determinants of longevity is limited, the general consensus is that longevity is a multifactorial quantitative trait that is influenced by biological, environmental, and psychosocial factors. ${ }^{2}$ Among all these elements, modifiable risk factors are especially relevant as they are amenable to intervention. Lifestyle, social networks, and leisure activities have been studied individually in relation to longevity in several studies and others have examined the possible association of these factors with longevity while taking into account their coexistence and interactions. ${ }^{3-14}$ Only a few studies, however, have examined the relation between the combinations of various modifiable factors and longevity. ${ }^{15-17}$ Among the previous studies that have included the oldest old population ( $\geq 85$ years) $)^{8-17}$ only four had an observational period longer than 10 years. ${ }^{89} 1216$

Briefly, studies have shown that lifestyle factors such as smoking, ${ }^{341011} 131416$ alcohol consumption, ${ }^{34}$ and body weight (both underweight and overweight), ${ }^{8}{ }^{16}$ can predict mortality in elderly people. However, it is uncertain whether these associations are applicable to the oldest old. Indeed, studies have indicated that the relation between certain lifestyle factors and mortality may differ among those aged 75 or older compared with younger adults. ${ }^{7-9} 14$ Results concerning the association between social network and mortality among the elderly population have been controversial. ${ }^{18}$ Finally, previous reports have supported the hypothesis that the associations between leisure time activity, especially physical activity, ${ }^{4-612} 1316$ and survival among the elderly population are positive, although these relations have not been confirmed in other studies. ${ }^{11}$

We examined the associations of independent and combinations of various modifiable factors with median age at death in a cohort aged 75 or more years at entry to the Kungsholmen Project in central Stockholm, Sweden, that was followed for 18 years. Unlike previous studies that reported the associations in terms of relative risks or hazard ratios, we used absolute values, such as differences in survival among different groups. 


\section{Methods}

The study was carried out as part of the Kungsholmen Project, a community based longitudinal study on aging and dementia. A detailed description of the study population and the baseline survey has been previously published. ${ }^{19}{ }^{20}$ Briefly, the initial cohort included all registered inhabitants in the Kungsholmen district of central Stockholm who were aged 75 years or older at baseline (October 1987). Of the 2368 eligible participants living at home or in institutions, 181 died, 69 moved out of the area before the baseline examination, and 308 refused to participate, leaving 1810 participants $(76.4 \%)$ who undertook the baseline survey for the current analysis.

\section{Data collection}

Data on personal characteristics (age, sex, occupation, and education) at baseline was obtained from participants through a face to face interview with trained nurses, following standard protocols. ${ }^{192}$ Educational level was measured as total years of formal schooling. Socioeconomic status was evaluated on the basis of both education and occupation. Education was divided into primary ( $<8$ years) and secondary or above ( $\geq 8$ years). We used a questionnaire developed by an expert in occupational medicine to assess occupation based socioeconomic status. Information collected about lifetime work activities included employer, job title, period of employment, and tasks for all jobs lasting at least six months. We grouped lifetime occupational experiences according to the Swedish socioeconomic classification system. ${ }^{21}$ The main occupation was defined as the longest job during lifetime, classified as manual work or non-manual work. ${ }^{22}$

Information on smoking and alcohol consumption was obtained from baseline data or, if information was missing at baseline, from data collected at the first follow-up three years after baseline. Smoking history was assessed by asking participants whether they had ever smoked. Smokers and former smokers were asked how long they had smoked and the number of cigarettes smoked per day. Former smokers were also asked at what age they had stopped smoking. We categorised smoking status as current, former, and never. ${ }^{23}$

Alcohol consumption was categorised as yes or no. At baseline, only $6 \%$ of the participants reported being heavy drinkers $(>168$ $\mathrm{g}$ ethanol per week for men and $>112 \mathrm{~g}$ ethanol per week for women). We calculated body mass index as weight $(\mathrm{kg})$ divided by the square of the height $(\mathrm{m})$ using direct measures, and we used standard cut-offs to categorise the participants as overweight (body mass index $>25$ ), of normal weight (20-25), or underweight $(<20) .^{24}$

Information on leisure activities and social networks was obtained from participants through face to face interviews carried out by trained nurses during the baseline survey. ${ }^{19} 20$ Participants were asked whether they regularly engaged in any particular activities or belonged to any organisations. If so, they were asked to specify the types of activities or organisations and to report the frequency of participation. We grouped the reported activities into mental, physical, social, and productive according to the classification adopted in previous studies. ${ }^{25}$ The frequency of participation in any leisure activities was initially recorded as daily, weekly, monthly, or annually. On the basis of the answers, we categorised the frequency as no participation, daily to weekly participation, and monthly participation. Owing to the statistical power of the study, we analysed survival in relation to participation in each type of activity (at least monthly) compared with no participation. Participants were assigned to a particular group if they participated in at least one of that group's activities. Mental activities included reading books or newspapers, writing, studying, doing crossword puzzles, painting, or drawing. Physical activities encompassed swimming, walking, or gymnastics. Social activities consisted of attending the theatre, concerts, or art exhibitions; traveling; playing cards or games; or participating in social groups or an organisation for older people. Productive activities included gardening, housekeeping, cooking, working for pay after retirement, doing volunteer work, and sewing, knitting, crocheting, or weaving.

To determine the extent of social networks, we asked participants about marital status, living arrangements, parenthood, and friendships. We also asked about frequency of contact with children and friends or relatives and how satisfied participants were with the frequency of those contacts. On the basis of their answers, we grouped the participants into the three social network categories of rich, moderate, and limited or poor. ${ }^{26}$ The group with a rich social network included those who were married and lived with someone, had children with whom they were in daily to weekly contact and found this level of contact satisfactory, and had relatives or friends with whom they were in daily to weekly contact and found this level of contact satisfactory. The group with a moderate social network included those who had any two of the three elements. The group with a limited or poor social network included those who had any one or none of the three elements.

If participants were not able to answer the questions (for example, they had cognitive impairment or dementia), then we interviewed an informant, usually someone who was next of kin.

We classified a disease as chronic if it had one or more of the following characteristics: was permanent; was caused by non-physiological changes leading to irreversible damage to a tissue, organ, or system; required rehabilitation; or required a long period of care. ${ }^{27}$ Multimorbidity was defined as the existence of two or more chronic diseases in one individual; we did not define index diseases. ${ }^{28} \mathrm{We}$ ascertained the participants' history of chronic diseases using the computerised Stockholm inpatient register system, which covers the period 1969 to 1989 (before baseline). The International Classification of Diseases (eighth revision) was used for all diagnoses in the inpatient register system.

Information about the vital status of the participants in 2005 was derived from death certificates provided by Statistics Sweden.

\section{Statistical analysis}

As participants entered in the study at various ages, we analysed baseline age as a confounder and not as a main exposure of interest in the analyses.

The median age at death was the age at which half of the participants had died and the other half were still alive. Survival time was censored for those who were still alive at the end of the study (31 August 2005). We used Laplace regression to model the median age at death as a function of lifestyle factors, leisure activities, and social network. ${ }^{29}$ Firstly, we estimated differences in median age at death separately by each modifiable factor in age adjusted models. Secondly, we simultaneously adjusted for all the modifiable factors and personal characteristics that were statistically significant in the age adjusted models. Because elderly people often experience chronic illnesses that can affect their lifestyle, we further adjusted for number of chronic conditions. ${ }^{28}$ 
Laplace regression is a statistical model that makes inferences on centiles (for example, median) of survival time conditionally on covariates, while taking into account the presence of censored observations. In the absence of covariates, Laplace regression provides estimates of survival centiles similar to the non-parametric Kaplan-Meier method. However, unlike Kaplan-Meier analysis, Laplace regression allows researchers to model the association between continuous exposures, adjusting for confounders, and to assess interactions in predicting survival time. ${ }^{30}$

The proportion of missing covariate data was $4 \%$ for leisure activities, $19 \%$ for body mass index, $28 \%$ for smoking, and $32 \%$ for alcohol consumption. We carried out a complete case analysis based on $60 \%$ of the cohort. A sensitivity analysis was done for missing data, with multivariate imputation by chained equations (MICE) to obtain 50 imputed datasets. ${ }^{31}$ We pooled the estimates using Rubin's rule to obtain valid statistical inferences. ${ }^{32}$ All the relevant variables included in the major analyses were used in the multiple imputation models, as was the outcome (age at death).

In the secondary analysis we investigated the relation between various combinations of modifiable factors and median age at death. We defined a reference group as participants with a high risk profile. This group included all participants who had unhealthy lifestyle factors (were overweight or underweight and were current or former smokers), a limited or poor social network, and did not engage in any leisure activities. We estimated median age at death for this group and then compared this with the median age at death for three other groups: those with a moderately high risk profile, those with a moderately low risk profile, and those with a low risk profile. The moderately high risk profile included those participants with at least two of the three risk factors and therefore included those active in at least one leisure activity but who had a poor or limited social network and unhealthy lifestyle factors; or those with a moderate or rich social network but who had unhealthy lifestyle factors and were not engaged in any leisure activities; or those with healthy lifestyle factors (normal weight and never smoked) but who had a limited or poor social network and were not engaged in any leisure activities. The moderately low risk profile included those with only one of the three risk factors and therefore included those active in at least one leisure activity and with a moderate or rich social network but with unhealthy lifestyle factors; or those with a moderate or rich social network and healthy lifestyle factors but who were not engaged in any leisure activities; or those with healthy lifestyle factors who were active in at least one leisure activity but who had a limited or poor social network. The low risk profile included those who had healthy lifestyle factors, had a rich or moderate social network, and engaged in at least one leisure activity.

\section{Results}

Table $1 \Downarrow$ shows the personal characteristics, lifestyle factors, extent of social networks, leisure activities, and health status of the participants by survival status at 18 years of follow-up. The mean (standard deviation) age at the end of follow-up was 96.1 (3.0) years for survivors and 89.5 (5.4) years for non-survivors. Survivors were more likely than non-survivors to be women, be highly educated, have healthy lifestyle factors, have a better social network, and participate in more leisure activities.

During the 18 years of follow-up, 149 (8.2\%) participants survived and $1661(91.8 \%)$ did not. Overall, $50 \%$ of the participants lived to be 90.0 years or older (median age at death).
Table $2 \Downarrow$ shows the differences in median age at death across the potentially relevant factors. In the age adjusted models, median age at death for participants of normal weight or who had never smoked was about one year longer than those who were underweight (difference in median age at death $-1.1,95 \%$ confidence interval -1.7 to -0.4$)$ and current smokers $(-1.3$, -2.2 to -0.4$)$. Participants who consumed alcohol survived a median of 1.3 years (95\% confidence interval 0.7 to 1.8 ) longer than never drinkers. Half of the participants with a rich social network lived at least 1.6 years $(95 \%$ confidence interval 0.8 to $2.5)$ longer than those with a limited or poor social network. Of all the leisure activities, physical activity was associated with the largest difference in median survival; those who were physically active survived more than two years longer than those who were physically inactive (differences in median age at death 2.3 years, $95 \%$ confidence interval 1.5 to 3.1 ).

The multivariable model controlled for all factors that were significantly associated with survival in the age adjusted models. The associations between most factors and survival remained similar in direction and magnitude, except for rich social network and mental activity where the differences in median survival were no longer statistically significant. Further adjustment for multimorbidity attenuated the differences in median survival. Social network did not follow this pattern, as after controlling for multimorbidity people with a rich social network clearly survived longer than people with a limited or poor social network. The magnitude and direction of the differences in median age at death based on the main analysis of complete data and the sensitivity analysis of multiple imputations were similar (table 2).

Table $3 \Downarrow$ shows the differences in median age at death between the group with the high risk profile (reference group) and the other three groups. The figure $\Downarrow$ shows the median age at death in all four groups for the entire population and stratified by sex, age at baseline, and number of chronic conditions. Overall, after age 75, lifestyle behaviours such as never smoking, participating in at least one leisure activity, and having frequent contact with children or friends and relatives (and being satisfied with this contact) were associated with survival. Median survival for those in the group with the low risk profile was almost five years longer than that in the group with the high risk profile (table 3 ). The median age at death was about 83 years for those with a high risk profile and 88 years for those with a low risk profile (figure). Stratified analysis by sex showed that the median age at death was higher for women than for men. The difference in median age at death between people with a low risk profile and those with a high risk profile was six years for men and five years for women (table 3 ). Stratification by age showed that even in the oldest old participants ( $\geq 85$ years) the median age at death was higher (4.7 years more) if participants belonged to the group with the low risk profile (table 3 ).

Finally, stratified analysis by health conditions revealed that the median age at death for participants with more than one chronic condition who belonged to the group with the low risk profile was 87 years, around five years older than those in the group with the high risk profile (median age at death 82 years, figure)

\section{Discussion}

In this longitudinal study of 1810 older participants followed up for 18 years, several lifestyle behaviours were associated with longevity, even after age 75 and independently of health status. Certain health behaviours remained predictive of survival even among the oldest old ( $\geq 85$ years) and those with 
multimorbidity. To the best of our knowledge this is the first study that directly provides information about differences in longevity according to several modifiable factors.

\section{Lifestyle factors and survival}

Smokers who survived to 75 years had a one year shorter median survival than those who had never smoked. In the Kungsholmen Project population, $83 \%$ of the former smokers had quit smoking 15 to 35 years before baseline and $17 \%$ had quit five to 14 years before baseline. The pattern of survival in all former smokers in the study population was the same as that of never smokers. In line with our results, previous studies have found an inverse association between smoking and survival among elderly people, ${ }^{11} 1316$ whereas other studies have failed to find an association. ${ }^{89}{ }^{12}$ Our results confirm the negative association between smoking and survival even in old age, and that quitting smoking in middle age reduces the effect on mortality. Because most former smokers in the study had quit smoking 15 to 35 years before baseline, it is not clear if quitting smoking five to 14 years before baseline may still be associated with survival in elderly people, although this seems to be suggested by our results.

\section{Leisure activities and survival}

The positive association between leisure activity, especially regular physical activity, and longevity found in our analysis confirms the results of some previous studies ${ }^{121316}$ but not others. ${ }^{11}$ Although the present analysis cannot provide a definite answer about whether the association between lack of physical activity and shorter survival reflects the effect of illness present at baseline, we were able to minimise the confounding effect by adjusting for morbidity and multimorbidity at baseline. After adjustment the association between physical activity and survival was still significant. Moreover, we cannot verify whether physical activity levels reported at baseline were important in themselves or were indicators of an individual's lifetime history of physical activity.

\section{Combinations of modifiable factors and survival}

Our results on the associations between various combinations of modifiable factors and median age at death showed that compared with their respective high risk profile groups, men with a low risk profile gained more years of survival than women with a low risk profile: the women by five years and the men by six years. Even among those aged 85 years or more, the median age at death could be four years higher if the participants had a healthy lifestyle, a rich or moderate social network, and engaged in at least one leisure activity. Finally, the median age at death for people with more than one chronic condition but who belonged to the group with the low risk profile was 87 years, five years later than those with a high risk profile.

Only a few studies have investigated the relation between combinations of modifiable factors and survival. In the Survey in Europe on Nutrition and the Elderly: a Concerted Action (SENECA) study, researchers developed a lifestyle score by combining three lifestyle factors (non-smoking, physical activity, and quality of diet) and found a strong relation between a healthy lifestyle score and survival. ${ }^{15}$ Another study pooled five healthy behaviours (based on smoking, alcohol consumption, diet, body mass index, and physical activity) and investigated the relation between this group of healthy behaviours and mortality. They found that the hazard ratio in men with a low lifestyle score was statistically higher than in men with a high lifestyle score. ${ }^{17}$ Researchers working with the Physicians' Health Study cohort found that the probability of surviving to age 90 was $54 \%$ for those with no adverse factors (those who had never smoked, had normal blood pressure and weight, did not have diabetes, and were moderately physically active).$^{16}$ Our results were similar to the results of those studies in which the probability of survival was significantly higher among those with the healthier lifestyle scores than among those with less healthy lifestyle scores.

\section{Strengths and limitations of the study}

The major strengths of our study were that the study population was from the general population, including people living at home and in institutions; the study design was prospective; the data on extensive modifiable factors were substantial; and follow-up was long-term. Additionally, we accounted for possible reverse causality by considering only the baseline ascertainment of chronic conditions. All previous studies have examined variation in the risk, hazard, or rate ratio of mortality in relation to selected modifiable factors. The interpretation of these commonly used measures of association may not be easy to communicate to patients or to the general public.

The drop-out rate at baseline of the Kungsholmen Project was $23.6 \%$ (558/2368), mainly due to refusal (12.4\%), death (7.6\%), and moving from the area $(3.6 \%)$. The personal characteristics of those who refused to participate and those who moved did not differ from those of the participants. Only the 181 who dropped out due to death differed from participants, as they were older and more often men. It is likely that those drop-outs led to an overestimation of the median age at death, especially for the oldest old ( $\geq 85$ years) men.

Any interpretation of the results needs to take survival selection into account ${ }^{33}$ (in this case before age 75). This is especially true for factors that show an inverse association with mortality. The positive associations with mortality are more likely to be simply underestimated. On the other hand, our study population included people who survived to at least 75 years, which enabled us to investigate the associations of independent and combinations of various modifiable factors with survival in a very old population ( $\geq 75$ years). This is particularly relevant given the limited current knowledge about the relations between such modifiable factors and longevity.

In our study only a small proportion of people had a high alcohol consumption. Thus alcohol consumption, which was mostly moderate, may have protected against mortality. However, because of the high rate of missing data $(32 \%)$ we cannot rule out the possibility that this result may be heavily affected by information bias. ${ }^{34}$

Although we adjusted for many factors potentially associated with longevity, our analysis did not include all variables that may be associated with longevity (such as quality of diet). Further analyses are also needed to examine the association between incident morbidity and survival. Moreover, we could not assess the relations between changes in modifiable factors over the lifespan and survival because we assessed exposures only at baseline. Furthermore, repeated measurements of exposure would have provided a better understanding about whether accumulation of factors over the lifetime affects the associations between lifestyle or social factors and survival. In addition, whether extra years of life gained through increased longevity are spent in good or bad health is a crucial question, which we did not address in this study. 
Ignoring missing data in complete case analysis can potentially lead to biased estimates. ${ }^{35}$ However, the small differences in the results of complete case and multiple imputation analyses in this study suggest that missing data had little impact on the observed findings.

\section{Conclusions}

The associations between leisure activity, not smoking, and increased survival still existed in those aged 75 years or more, with women's lives prolonged by five years and men's by six years. These associations, although attenuated, were still present among people aged 85 or more and in those with chronic conditions. Our results suggest that encouraging favourable lifestyle behaviours even at advanced ages may enhance life expectancy, probably by reducing morbidity.

We thank the members of the Kungsholmen Project study group for data collection and Kimberly Kane (scientific editor) for useful comments on the text.

Contributors: DR and LF designed the study. DR and NO did the statistical analyses. DR drafted the manuscript. All authors critically revised the manuscript for important and intellectual content. DR is the guarantor.

Funding: This study was funded by the Swedish Council for Working Life and Social Research, Swedish Research Council for Medicine, Swedish Brain Power, Karolinska Institutet's Faculty funding for postgraduate students, and the Stiftelsen Ragnhild och Einar Lundströms Minne. The sponsor had no role in study design, data collection, data analysis, data interpretation, the writing of the report, or in the decision to submit the paper for publication. The corresponding author had full access to all the data in the study and had final responsibility for the decision to submit for publication.

Competing interests: All authors have completed the ICMJE uniform disclosure form at www.icmje.org/coi_disclosure.pdf (available on request from the corresponding author) and declare: no support from any organisation for the submitted work; no financial relationships with any organisations that might have an interest in the submitted work in the previous three years; and no other relationships or activities that could appear to have influenced the submitted work.

Ethical approval: This study was approved by the ethics committee of Karolinska Institutet, and informed consent was obtained from all participants (87:148; 87:234; 90:251; 94:122, 97:413, and 99:308).

Data sharing: No additional data available.

1 Rousson V, Paccaud F. A set of indicators for decomposing the secular increase of life expectancy. Popul Health Metr 2010;8:18.

2 Candore G, Balistreri CR, Listi F, Grimaldi MP, Vasto S, Colonna-Romano G, et al. Immunogenetics, gender, and longevity. Ann N Y Acad Sci 2006;1089:516-37.

3 Halme JT, Seppa K, Alho H, Poikolainen K, Pirkola S, Aalto M. Alcohol consumption and all-cause mortality among elderly in Finland. Drug Alcohol Depend 2010;106:212-8.

4 Ruigomez A, Alonso J, Anto JM. Relationship of health behaviours to five-year mortality in an elderly cohort. Age Ageing 1995;24:113-9.

5 Rodriguez-Laso A, Zunzunegui MV, Otero A. The effect of social relationships on survival in elderly residents of a southern European community: a cohort study. BMC Geriatr 2007;7:19.

6 Fried LP, Kronmal RA, Newman AB, Bild DE, Mittelmark MB, Polak JF, et al. Risk factors for 5-year mortality in older adults: the Cardiovascular Health Study. JAMA 1998:279:585-92.

7 Menotti A, Kromhout D, Nissinen A, Giampaoli S, Seccareccia F, Feskens E, et al. Short-term all-cause mortality and its determinants in elderly male populations in Finland,
The Netherlands, and Italy: the FINE Study. Finland, Italy, Netherlands Elderly Study. Prev Med 1996;25:319-26.

8 Nybo H, Petersen HC, Gaist D, Jeune B, Andersen K, McGue M, et al. Predictors of mortality in 2,249 nonagenarians-the Danish 1905-Cohort Survey. J Am Geriatr Soc 2003;51:1365-73.

9 Hagberg B, Samuelsson G. Survival after 100 years of age: a multivariate model of exceptional survival in Swedish centenarians. J Gerontol A Biol Sci Med Sci 2008:63:1219-26.

10 Newson RS, Witteman JC, Franco OH, Stricker BH, Breteler MM, Hofman A, et al. Predicting survival and morbidity-free survival to very old age. Age (Dordr) 2010;32:521-34. 1 De Groot LC, Verheijden MW, de Henauw S, Schroll M, van Staveren WA. Lifestyle, nutritional status, health, and mortality in elderly people across Europe: a review of the longitudinal results of the SENECA study. J Gerontol A Biol Sci Med Sci 2004;59:1277-84.

12 Benetos A, Thomas F, Bean KE, Pannier B, Guize L. Role of modifiable risk factors in life expectancy in the elderly. J Hypertens 2005;23:1803-8.

13 Knoops KT, de Groot LC, Kromhout D, Perrin AE, Moreiras-Varela O, Menotti A, et al. Mediterranean diet, lifestyle factors, and 10-year mortality in elderly European men and women: the HALE project. JAMA 2004;292:1433-9.

14 Dupre ME, Liu G, Gu D. Predictors of longevity: evidence from the oldest old in China. Am J Public Health 2008:98:1203-8.

15 Haveman-Nies A, de Groot LP, Burema J, Cruz JA, Osler M, van Staveren WA. Dietary quality and lifestyle factors in relation to 10-year mortality in older Europeans: the SENECA study. Am J Epidemiol 2002;156:962-8.

16 Yates LB, Djousse L, Kurth T, Buring JE, Gaziano JM. Exceptional longevity in men: modifiable factors associated with survival and function to age 90 years. Arch Intern Med 2008;168:284-90.

17 Spencer CA, Jamrozik K, Norman PE, Lawrence-Brown M. A simple lifestyle score predicts survival in healthy elderly men. Prev Med 2005;40:712-7.

18 Holt-Lunstad J, Smith TB, Layton JB. Social relationships and mortality risk: a meta-analytic review. PLoS Med 2010;7:e1000316.

19 Fratiglioni L, Viitanen M, Backman L, Sandman PO, Winblad B. Occurrence of dementia in advanced age: the study design of the Kungsholmen Project. Neuroepidemiology 1992;11(Suppl 1):29-36.

20 Fratiglioni L, Viitanen M, von Strauss E, Tontodonati V, Herlitz A, Winblad B. Very old women at highest risk of dementia and Alzheimer's disease: incidence data from the Kungsholmen Project, Stockholm. Neurology 1997;48:132-8.

21 Statistics Sweden. Swedish socio-economic classification (SSI). Published in Reports on Statistical Co-ordination, 1982:4:6 (English summary).

22 Karp A, Kareholt I, Quu C, Bellander T, Winblad B, Fratiglioni L. Relation of education and occupation-based socioeconomic status to incident Alzheimer's disease. Am J Epidemiol 2004;159:175-83.

23 Wang HX, Fratiglioni L, Frisoni GB, Viitanen M, Winblad B. Smoking and the occurrence of Alzheimer's disease: cross-sectional and longitudinal data in a population-based study. Am J Epidemiol 1999;149:640-4.

24 Diehr P, Newman AB, Jackson SA, Kuller L, Powe N. Weight-modification trials in older adults: what should the outcome measure be? Curr Control Trials Cardiovasc Med 2002;3:1.

25 Wang HX, Karp A, Winblad B, Fratiglioni L. Late-life engagement in social and leisure activities is associated with a decreased risk of dementia: a longitudinal study from the Kungsholmen project. Am J Epidemiol 2002;155:1081-7.

26 Fratiglioni L, Wang HX, Ericsson K, Maytan M, Winblad B. Influence of social network on occurrence of dementia: a community-based longitudinal study. Lancet 2000;355:1315-9.

27 Timmreck TC, Cole GE, James G, Butterworth DD. Health education and health promotion: a look at the jungle of supportive fields, philosophies and theoretical foundations. Health Educ 1987; 18:23-8.

28 Marengoni A, Angleman S, Melis R, Mangialasche F, Karp A, Garmen A, et al. Aging with multimorbidity: a systematic review of the literature. Ageing Res Rev 2011;10:430-9.

29 Bottai M, Zhang J. Laplace regression with censored data. Biom J 52:487-503.

30 Orsini N, Wolk A, Bottai M. Evaluating percentiles of survival. Epidemiology 2012;23:770-1.

31 Van Buuren S, Boshuizen HC, Knook DL. Multiple imputation of missing blood pressure covariates in survival analysis. Stat Med 1999;18:681-94.

32 Rubin DB, Schenker N. Multiple imputation for interval estimation from simple random samples with ignorable nonresponse. J Am Stat Assoc 1986;81;366-74.

33 Glymour MM, Weuve J, Chen JT. Methodological challenges in causal research on racial and ethnic patterns of cognitive trajectories: measurement, selection, and bias. Neuropsychol Rev 2008;18:194-213.

34 Huang W, Qui C, Winblad B, Fratiglioni L. Alcohol consumption and incidence of dementia in a community sample aged 75 years and older. J Clin Epidemiol 2002;55:959-64.

35 Demissie S, LaValley MP, Horton NJ, Glynn RJ, Cupples LA. Bias due to missing exposure data using complete-case analysis in the proportional hazards regression model. Stat Med 2003;22:545-57.

\section{Accepted: 13 August 2012}

\section{Cite this as: BMJ 2012;345:e5568}

This is an open-access article distributed under the terms of the Creative Commons Attribution Non-commercial License, which permits use, distribution, and reproduction in any medium, provided the original work is properly cited, the use is non commercial and is otherwise in compliance with the license. See: http://creativecommons.org/licenses/by$\mathrm{nc} / 2.0 /$ and http://creativecommons.org/licenses/by-nc/2.0/legalcode. 


\section{What is already known on this topic}

Lifestyle factors such as smoking, alcohol consumption, and being underweight or overweight predict mortality among the elderly population

It is uncertain whether these associations are applicable to the oldest old ( $\geq 85$ years) because of mixed results

\section{What this study adds}

Lifestyle behaviours such as smoking and physical activity predict survival even after age 75

The associations of leisure activity and not smoking with increased life expectancy were still present among those aged 85 or more and those with chronic conditions

\section{Tables}

\begin{tabular}{|c|c|c|c|}
\hline Characteristics & Total $(n=1810)$ & No $(\%)$ alive $(n=149)$ & No $(\%)$ who died $(n=1161)$ \\
\hline Mean (SD) age at end of follow-up (years) & - & $96.1(3.0)$ & $89.5(5.4)$ \\
\hline \multicolumn{4}{|l|}{ Sex: } \\
\hline Women & $1378(76.1)$ & $129(9.4)$ & $1249(90.6)$ \\
\hline Men & $432(23.9)$ & $20(4.6)$ & $412(95.4)$ \\
\hline \multicolumn{4}{|l|}{ Education (years): } \\
\hline$<8$ & $958(53.5)$ & $60(6.3)$ & $898(93.7)$ \\
\hline$\geq 8$ & $834(46.5)$ & $86(10.3)$ & $748(89.7)$ \\
\hline \multicolumn{4}{|l|}{ Socioeconomic status: } \\
\hline Non-manual & $592(63.6)$ & $48(8.1)$ & $544(91.9)$ \\
\hline Manual & $339(36.4)$ & $23(6.8)$ & $316(93.2)$ \\
\hline \multicolumn{4}{|l|}{ Lifestyle factors } \\
\hline \multicolumn{4}{|l|}{ Body mass index: } \\
\hline$<20$ (underweight) & $237(16.1)$ & $10(4.2)$ & $227(95.8)$ \\
\hline 20-25 (normal weight) & $770(52.4)$ & $83(10.8)$ & $687(89.2)$ \\
\hline$\geq 25$ (overweight) & $462(31.5)$ & $46(10.0)$ & $416(90.0)$ \\
\hline \multicolumn{4}{|l|}{ Smoking status: } \\
\hline Never smoked & $957(73.9)$ & $83(8.7)$ & $874(91.3)$ \\
\hline Former smoker & $186(14.4)$ & $15(8.1)$ & $171(91.9)$ \\
\hline Current smoker & $152(11.7)$ & $7(4.6)$ & $145(95.4)$ \\
\hline \multicolumn{4}{|l|}{ Alcohol consumption: } \\
\hline Yes & $805(65.4)$ & $78(9.7)$ & $727(90.3)$ \\
\hline No & $425(34.6)$ & $25(5.9)$ & $400(94.1)$ \\
\hline \multicolumn{4}{|l|}{ Social network: } \\
\hline Rich & $105(5.8)$ & $16(15.2)$ & $89(84.8)$ \\
\hline Moderate & $1350(74.6)$ & $110(8.2)$ & $1240(91.8)$ \\
\hline Limited or poor & 355 (19.6) & $23(6.5)$ & 332 (93.5) \\
\hline \multicolumn{4}{|l|}{ Leisure activities } \\
\hline \multicolumn{4}{|l|}{ Mental: } \\
\hline Yes & $713(41.2)$ & $68(9.5)$ & $645(90.5)$ \\
\hline No & $1016(58.8)$ & $81(8.0)$ & $935(92.0)$ \\
\hline \multicolumn{4}{|l|}{ Social: } \\
\hline Yes & $355(20.5)$ & $50(14.1)$ & $305(85.9)$ \\
\hline No & $1374(79.5)$ & $99(7.2)$ & $1275(92.8)$ \\
\hline \multicolumn{4}{|l|}{ Physical: } \\
\hline Yes & $146(8.4)$ & $25(17.1)$ & $121(82.9)$ \\
\hline No & $1583(91.6)$ & $124(7.8)$ & $1459(92.2)$ \\
\hline
\end{tabular}


Table 1 (continued)

\begin{tabular}{|c|c|c|c|}
\hline Characteristics & Total $(n=1810)$ & No $(\%)$ alive $(n=149)$ & No $(\%)$ who died $(n=1161)$ \\
\hline Yes & $501(29.0)$ & $61(12.2)$ & $440(87.8)$ \\
\hline No & $1228(71.0)$ & $88(7.2)$ & $1140(92.8)$ \\
\hline \multicolumn{4}{|l|}{ Health status } \\
\hline \multicolumn{4}{|c|}{ No of chronic conditions*: } \\
\hline 0 & $660(36.5)$ & $92(13.9)$ & $568(86.1)$ \\
\hline 1 & $474(26.2)$ & $46(9.7)$ & $428(90.3)$ \\
\hline$\geq 2$ & 676 (37.3) & $11(1.6)$ & $665(98.4)$ \\
\hline
\end{tabular}

*Included malignancy, respiratory tract disease, mental disorders, endocrine disease, blood disease, neurosensorial disease, musculoskeletal disease, cardiovascular disease, urological disorders, and digestive disorders. 


\begin{tabular}{|c|c|c|c|c|}
\hline \multirow[b]{2}{*}{ Variables } & \multicolumn{4}{|c|}{ Differences $(95 \% \mathrm{Cl})$ in median age at death (years) } \\
\hline & Age adjusted & Multivariate adjusted* & $\begin{array}{c}\text { Multivariate } \\
\text { adjusted+multimorbidity }\end{array}$ & Multiple imputation $†$ \\
\hline \multicolumn{5}{|l|}{ Personal characteristics: } \\
\hline Women $v$ men & $1.8(1.5$ to 2.2$) \ddagger$ & $2.4(1.7$ to 3.2$) \ddagger$ & $2.2(1.3$ to 3.1$) \ddagger$ & 2.0 (1.3 to 2.7$) \ddagger$ \\
\hline High $v$ low education & $1.0(0.7$ to 1.3$) \ddagger$ & $0.9(0.2$ to 1.7$) \ddagger$ & $0.7(-0.1$ to 1.5$)$ & $0.4(-0.3$ to 1.0$)$ \\
\hline Non-manual $v$ manual work & $0.4(-0.3$ to 1.2$)$ & $-\S$ & $-\S$ & $-\S$ \\
\hline \multicolumn{5}{|l|}{ Lifestyle factors: } \\
\hline Underweight $v$ normal weight & $-1.1(-1.7$ to -0.4$) \ddagger$ & $-1.5(-2.4$ to -0.6$) \ddagger$ & $-0.8(-1.7$ to 0.2$)$ & $-0.6(-1.4$ to 0.3$)$ \\
\hline Overweight $v$ normal weight & $0.0(-0.6$ to 0.6$)$ & $-0.4(-1.2$ to 0.4$)$ & $-0.1(-0.8$ to 0.8$)$ & $0.2(-0.6$ to 1.0$)$ \\
\hline Former $v$ never smokers & $0.3(-0.5$ to 1.0$)$ & $0.3(-0.6$ to 1.3$)$ & $0.2(-0.7$ to 1.1$)$ & $0.7(-0.3$ to 1.6$)$ \\
\hline Current $v$ never smokers & $-1.3(-2.2$ to -0.4$) \ddagger$ & $-0.9(-1.9$ to -0.0$) \ddagger$ & $-0.7(-1.7$ to 0.2$)$ & $-1.2(-2.2$ to -0.2$) \ddagger$ \\
\hline Alcohol $v$ no alcohol consumers & $1.3(0.7$ to 1.8$) \ddagger$ & $0.8(0.1$ to 1.6$) \ddagger$ & $0.5(-0.3$ to 1.2$)$ & $0.5(-0.2$ to 1.2$)$ \\
\hline \multicolumn{5}{|l|}{ Social networks: } \\
\hline Rich $v$ limited or poor & $1.6(0.8$ to 2.5$) \ddagger$ & $0.7(-0.6$ to 2.1$)$ & $1.9(0.6$ to 3.2$) \ddagger$ & $2.7(0.9$ to 4.6$) \ddagger$ \\
\hline Moderate $v$ limited or poor & $0.0(-0.6$ to 0.6$)$ & $-0.5(-1.4$ to 0.3$)$ & $-0.5(-1.2$ to 0.3$)$ & $0.4(-0.4$ to 1.1$)$ \\
\hline \multicolumn{5}{|l|}{ Leisure activities (yes $v$ no): } \\
\hline Mental & $1.0(0.7$ to 1.3$) \ddagger$ & $0.0(-0.7$ to 0.8$)$ & $-0.1(-0.8$ to 0.6$)$ & $0.3(-0.3$ to 0.9$)$ \\
\hline Social & $1.8(1.3$ to 2.2$) \ddagger$ & $0.9(0.0$ to 1.7$) \ddagger$ & $1.0(0.1$ to 1.8$) \ddagger$ & $1.1(0.4$ to 1.8$) \ddagger$ \\
\hline Physical & $2.3(1.5$ to 3.1$) \ddagger$ & $2.0(0.7$ to 3.3$) \ddagger$ & $1.4(0.2$ to 2.7$) \ddagger$ & $1.9(0.6$ to 3.1$) \ddagger$ \\
\hline Productive & $1.3(0.8$ to 1.8$) \ddagger$ & $1.2(0.3$ to 2.1$) \ddagger$ & $0.9(0.1$ to 1.7$) \ddagger$ & $1.1(0.3$ to 1.9$) \ddagger$ \\
\hline \multicolumn{5}{|l|}{ Health status $\uparrow:$} \\
\hline $1 v 0$ chronic conditions & $-2.0(-2.4$ to -1.6$) \ddagger$ & $-\S$ & $-0.6(-1.6$ to 0.3$)$ & $-1.4(-2.2$ to -0.5$) \ddagger$ \\
\hline$\geq 2 \vee 0$ chronic conditions & $-4.7(-5.2$ to -4.2$) \ddagger$ & $-\S$ & $-2.7(-3.8$ to -2.0$) \ddagger$ & $-3.7(-4.4$ to -3.0$) \ddagger$ \\
\hline
\end{tabular}

*Adjusted for all variables that were statistically significant in age adjusted models.

†Multiple imputation analysis based on 50 imputed datasets and estimates combined using Rubin's method. All variables included in age adjusted models were used in multiple imputation models. The model was adjusted for all variables that were statistically significant in age adjusted models and for multimorbidity. $\ddagger \mathrm{P}<0.05$.

$\S$ No estimate available because the factor was not included in the model.

IIncluded malignancy, respiratory tract disease, mental disorders, endocrine disease, blood disease, neurosensorial disease, musculoskeletal disease, cardiovascular disease, urological disorders, and digestive disorders. 
Table 3| Differences in median age at death at $\mathbf{1 8}$ years of follow-up for four risk profile groups, in entire population and in strata by sex, age groups, and health status

\begin{tabular}{|c|c|c|c|c|}
\hline \multirow[b]{2}{*}{ Variables } & \multirow[b]{2}{*}{ High risk profile $(n=30)$} & \multicolumn{3}{|c|}{ Differences $(95 \% \mathrm{Cl})$ in median age at death (years) ${ }^{*}$} \\
\hline & & $\begin{array}{l}\text { Moderately high risk profile } \\
\qquad(\mathrm{n}=182)\end{array}$ & $\begin{array}{l}\text { Moderately low risk profile } \\
\qquad(\mathrm{n}=281)\end{array}$ & Low risk profile $(n=48)$ \\
\hline Entire population & Reference & $2.1(1.1$ to 3.1$) \dagger$ & $3.6(2.6$ to 4.6$) \dagger$ & $5.4(3.0$ to 7.8$) \dagger$ \\
\hline \multicolumn{5}{|l|}{ Stratified by sex: } \\
\hline Women & Reference & $2.0(0.8$ to 3.2$) \dagger$ & $3.3(2.1$ to 4.5$) \dagger$ & $5.3(3.1$ to 7.6$) \dagger$ \\
\hline Men & Reference & $2.4(0.7$ to 4.0$) \dagger$ & $3.6(2.1$ to 5.1$) \dagger$ & $6.3(-1.4$ to 14.0$)$ \\
\hline \multicolumn{5}{|c|}{ Stratified by age (years): } \\
\hline $75-84$ & Reference & $2.2(0.8$ to 3.5$) \dagger$ & $3.5(2.2$ to 4.8$) \dagger$ & $6.1(4.1$ to 8.1$) \dagger$ \\
\hline$\geq 85$ & Reference & $0.9(-0.5$ to 2.2$)$ & $3.0(1.4$ to 4.5$) \dagger$ & $4.0(0.8$ to 7.2$) \dagger$ \\
\hline \multicolumn{5}{|c|}{$\begin{array}{l}\text { Stratified by No of chronic } \\
\text { conditions } \neq \text { : }\end{array}$} \\
\hline 0 & Reference & $1.0(-1.0$ to 3.1$)$ & $1.0(-1.1$ to 3.2$)$ & $3.0(0.7$ to 5.4$) \dagger$ \\
\hline$\geq 1$ & Reference & $1.3(0.2$ to 2.4$) \dagger$ & $3.7(2.6$ to 4.9$) \dagger$ & $4.7(0.9$ to 8.4$) \dagger$ \\
\hline
\end{tabular}

Low risk profile=healthy lifestyle behaviours, participation in at least one leisure activity, and a rich or moderate social network; high risk profile=unhealthy lifestyle behaviours, no participation in leisure activities, and a limited or poor social network.

${ }^{*}$ Results were adjusted for education and, if applicable, for age and sex.

$\dagger P<0.05$.

ҒIncluded malignancy, respiratory tract disease, mental disorders, endocrine disease, blood disease, neurosensorial disease, musculoskeletal disease, cardiovascular disease, urological disorders, and digestive disorders. 


\section{Figure}

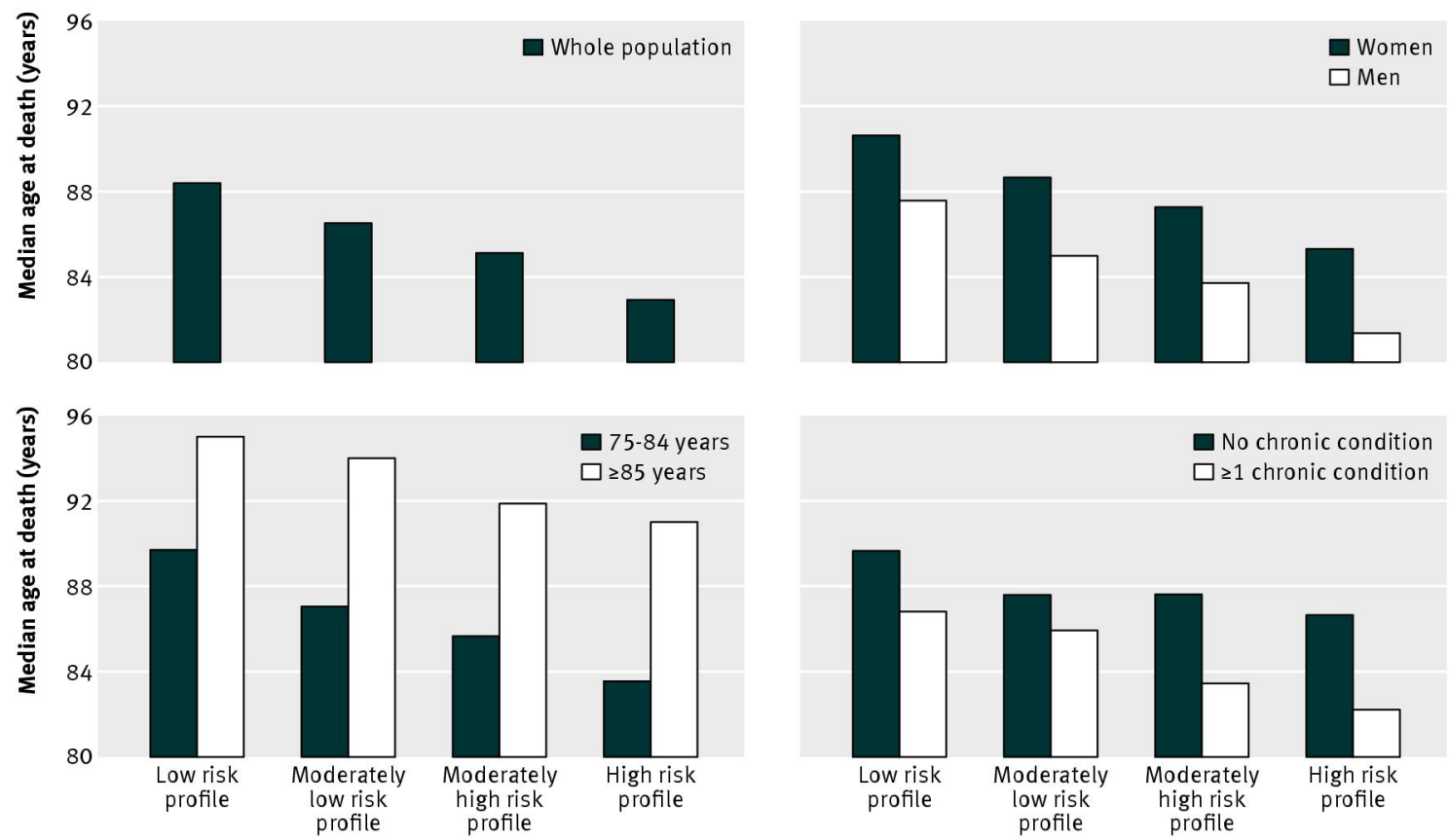

Median age at death in four risk groups according to combinations of modifiable factors among entire population, men and women separately, older adults (75-84 years) and oldest old adults ( $\geq 85$ years), and by status of chronic conditions. Results were from Laplace regression, adjusted for education 